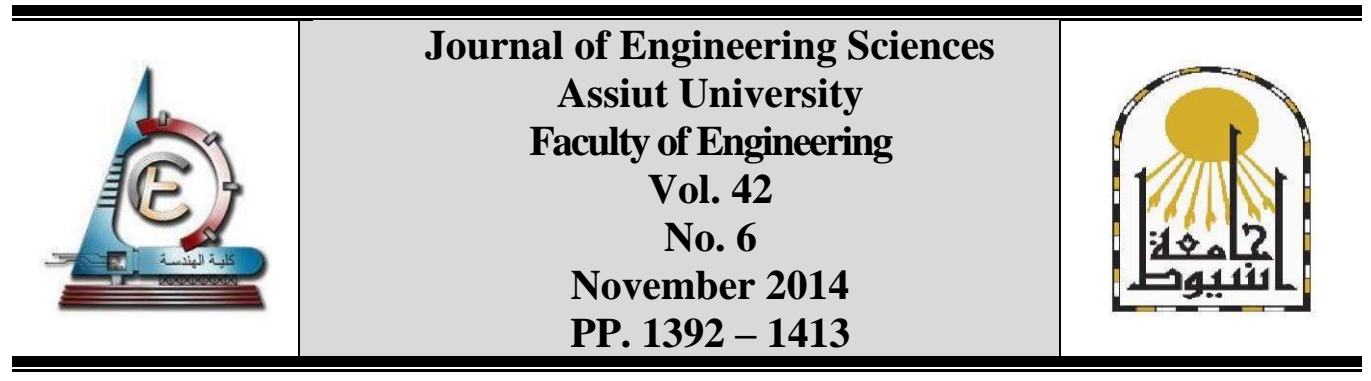

\title{
A PROPOSED DESIGN OF UWB MONOPOLE ANTENNA AND ITS LINEAR ARRAYS
}

\author{
Hosny El Metaafy ${ }^{1}$, Mahmoud Mohana ${ }^{2}$, \\ Ali Gomaa ${ }^{3}$, Mamdouh Shaker Yacoub ${ }^{4}$ and Gamal Kassem ${ }^{*}, 5$ \\ ${ }^{1,5}$ Higher Technological Institute $10^{\text {th }}$ of Ramadan city (H.T.I) \\ ${ }^{2}$ National Research Institute of Astronomy and geophysics (NRIAG) \\ ${ }^{3}$ Faculty of Engineering, Shoubra, Benha University \\ ${ }^{4}$ High Obour Institute
}

(Received 12 November 2014; Revised 12 December 2014; Accepted 15 December 2014)

\begin{abstract}
A proposed design of ultra-wideband (UWB) monopole antenna has been presented to cover frequency range 2.49-14.42 GHz with small size. An equivalent circuit model with the parameter values of the optimized UWB antenna has been modeled. Moreover, a compatible lumped-elements utilized in equivalent circuit modeling for the proposed monopole antenna is established using the Advanced Design System (ADS). An UWB feeding network circuit has been designed in order to be used for exciting $2 \times 1$ and $4 \times 1$ linear antenna array. The measured and simulated results for the proposed feed network has a good return loss, isolation and power division ratio at all ports within the whole UWB frequency range. Two and four element UWB linear antenna arrays are presented. The average gain for the two-element antenna array is about $5.3 \mathrm{dBi}$ and reaches to $7.15 \mathrm{dBi}$ for the four-element antenna array, over the whole UWB frequency range. A good agreement between the measured and the simulated results of all parameters for the antenna element and antenna arrays is appeared.
\end{abstract}

Keywords: monopole antenna, Ultra-wide band, antenna array, power divider, stubs matching.

\section{Introduction}

Recently, the unlicensed Ultra-wideband (UWB) technology for commercial communications released by the Federal Communication Commission (FCC) is used in several applications. The concept of UWB radio was first developed several decades ago exactly in the late1960's. The U.S. Development of Defense first founded the term 'Ultra wideband' in 1989 [1]. In the beginning, UWB was mainly for military purposes such as radar applications which use wideband signals in frequency domain or very short duration pulses in the time domain to get fast, reliable and accurate information about moving targets such missiles. UWB technology has a great interest especially in 2002 since the US Federal Communication Commission (FCC) allowed the using of the unlicensed frequency

* Corresponding author.

E-mail address: gamalkasem1956@yahoo.com 
band starting from 3.1 to $10.6 \mathrm{GHz}$ for commercial communication applications [2]. The allocated FCC bandwidth is $7.5 \mathrm{GHz}$ which represent $110 \%$ fractional bandwidth of the center frequency. Ultra wide band technology plays a paramount role in the development of modern wireless communication devices by transmitting videos, audios and other high bandwidth data between multiples of devices in the vicinity of $10 \mathrm{~m}$ or $30 \mathrm{ft}$, which covers the appliances used in home or office achieving high speed transfer, between 40 to 60 megabits per seconds and recently may reach up to 1 gigabits per second, low cost and low power consumption $(0.5 \mathrm{~mW})$. The major applications for the UWB are the commercial communication systems, like vehicular radar systems, imaging systems such as groundpenetrating radar, wall-imaging systems, medical systems, and surveillance systems. Also, in Wireless Personal Area Networks (WPANs) environments, UWB technology is an excellent solution for the ultra-high-speed data services up to $500 \mathrm{Mbps}$. These speeds can be greatly increased by using antenna arrays instead of single antenna element and different beam forming techniques. In order to design UWB antenna array, the power divider circuits are required. The most popular power divider is the Wilkinson power divider [3]. However, it operates only in a narrow bandwidth so; it is a serious problem for the UWB application. In order to achieve the bandwidth of UWB $(3.1-10.6 \mathrm{GHz})$, a threesection Wilkinson power divider has been reported, which increases the bandwidth [4]. Many efforts have been introduced to meet this challenge. One is to use a narrow rectangle slot to couple the wave from the input to output ports [5]. Also, adding open stubs can broaden the bandwidth. By placing one open stub at the center of each branch, the $\mathrm{n}^{\text {th }}$ harmonic component is suppressed [6]. Also, one can use additional transmission lines and open stubs to increase the bandwidth [7]. But both of them just reconstruct the circuit of the single-section Wilkinson power divider. Many UWB antennas have been reported in recent years [12-16]. Many UWB antenna arrays have been reported in recent years [1720]. The proposed antenna shown in Fig. 1 has been simulated by CST simulation software and fabricated on FR4 substrate with $\mathrm{h}=1.5 \mathrm{~mm}$ and $\varepsilon_{\mathrm{r}}=4.5$. All measurements are measured by using STARLAB18 in Scientific and Technology Center of Excellence (STCE) Egypt compact multi probe antenna test station.

\section{Effect of design parameters}

It has been shown in the simulation result that the operating band width of the proposed monopole antenna dependent on many effective parameters such as $\mathrm{L}_{\mathrm{f}}, \mathrm{L}_{\mathrm{g}}, \mathrm{L}_{\mathrm{t}}, \mathrm{W}_{\mathrm{t} 2}, \mathrm{~W}_{\mathrm{g}}, \mathrm{r}$, $\mathrm{L}_{1}, \mathrm{~L}_{2}, \mathrm{~W}_{1}$, and $\mathrm{W}_{2}$ as shown at Fig.1. A parametric study has been done for ten independent parameters and the dielectric substrate material and substrate height are kept constant at 4.5 and $1.5 \mathrm{~mm}$ respectively. The parametric study has been done utilizing the CST Microwave Studio [8]. The effect of each parameter individually where the other parameters are kept constant, on the matching of the antenna is presented in next section.

\subsection{Effect of the microstrip feed line $\left(L_{f}\right)$.}

Fig.2 shows investigation of the influence of the microstrip feed line $\left(\mathrm{L}_{\mathrm{f}}\right)$ dimensions. Four values of the microstrip feed line $\left(\mathrm{L}_{\mathrm{f}}\right)$ are assumed $(11.5,12.5,13.5$ and $14.5 \mathrm{~mm})$. The values $\mathrm{L}_{\mathrm{g}}, \mathrm{L}_{\mathrm{t}}, \mathrm{W}_{\mathrm{t} 2}, \mathrm{~W}_{\mathrm{g}}, \mathrm{r}, \mathrm{L}_{1}, \mathrm{~L}_{2}, \mathrm{~W}_{1}$, and $\mathrm{W}_{2}$ are kept constant at $10.8 \mathrm{~mm}, 9.4 \mathrm{~mm}, 1.2 \mathrm{~mm}$, $30 \mathrm{~mm}, 7.5 \mathrm{~mm}, 2.5 \mathrm{~mm}, 2.5 \mathrm{~mm}, 3.6 \mathrm{~mm}$, and $1 \mathrm{~mm}$ respectively. It is clear that as the microstrip feed line $\left(\mathrm{L}_{\mathrm{f}}\right)$ increases the impedance band width at the lower and upper resonant frequency bands decreased then it increased until we get the optimal value of $\mathrm{L}_{\mathrm{f}}=12.5 \mathrm{~mm}$. 


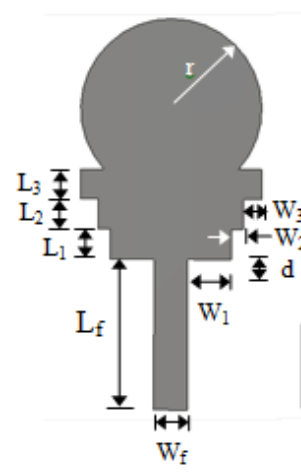

(ख)
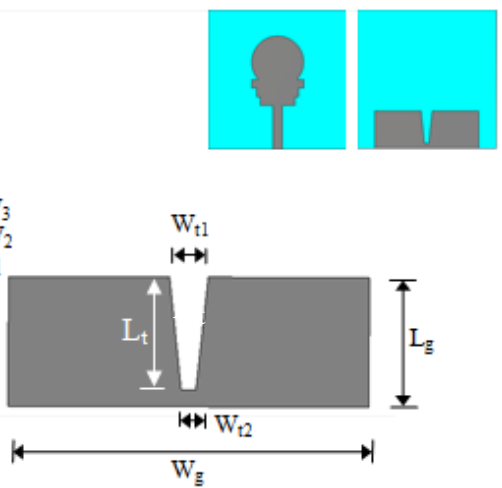

(b)

Fig.1. The geometry of the proposed UWB antenna structure:

(a) Patch layer (b) Ground plane layer.

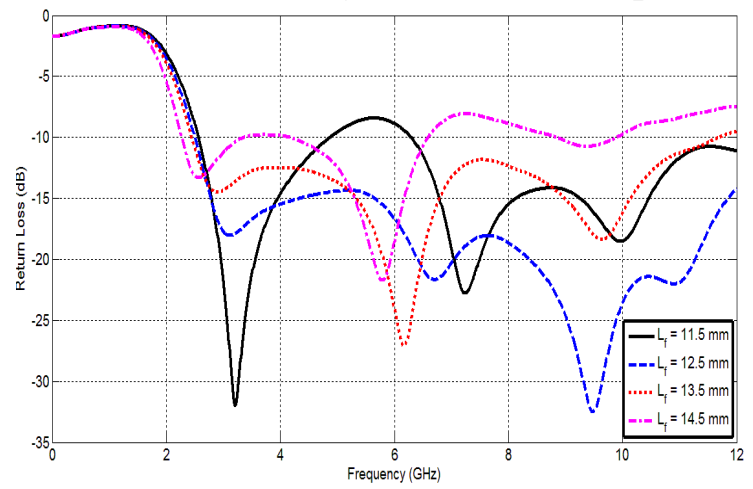

Fig.2. Parametric study of the microstrip feed line $\left(\mathrm{L}_{\mathrm{f}}\right)$ dimensions.

\subsection{Effect of the ground plane length $\left(L_{g}\right)$.}

Fig. 3 shows investigation of the influence of the ground plane length $\left(\mathrm{L}_{\mathrm{g}}\right)$ dimensions. Three values of the ground plane length $\left(\mathrm{L}_{\mathrm{g}}\right)$ are assumed $(9.8,10.8$, and $11.8 \mathrm{~mm})$. The values $\mathrm{L}_{\mathrm{f}}, \mathrm{L}_{\mathrm{t}}, \mathrm{W}_{\mathrm{t}}, \mathrm{W}_{\mathrm{g}}, \mathrm{r}, \mathrm{L}_{1}, \mathrm{~L}_{2}, \mathrm{~W}_{1}$, and $\mathrm{W}_{2}$ are kept constant at $12.5 \mathrm{~mm}, 9.4 \mathrm{~mm}, 1.2 \mathrm{~mm}, 30$ $\mathrm{mm}, 7.5 \mathrm{~mm}, 2.5 \mathrm{~mm}, 2.5 \mathrm{~mm}, 3.6 \mathrm{~mm}$, and $1 \mathrm{~mm}$ respectively. It is clear from the Fig. 3 that at the lower vales the ground plane length $\left(\mathrm{L}_{\mathrm{g}}\right)$ a less matching occurred at the lower operating impedance band width while at the high /large vales the ground plane length $\left(\mathrm{L}_{\mathrm{g}}\right)$ the less matching occurred at the shifted values of the operating impedance band width.

\subsection{Effect of the length of the etched tapper $\left(L_{t}\right)$ on the ground plane.}

Fig.4 shows investigation of the influence of the length of the etched tapper $\left(\mathrm{L}_{t}\right)$ on the ground plane dimensions. Four values of the length of the etched tapper $\left(\mathrm{L}_{\mathrm{t}}\right)$ on the ground plane are assumed $(3.4,5.4,7.4$, and $9.4 \mathrm{~mm})$. The values $\mathrm{L}_{\mathrm{f}}, \mathrm{L}_{\mathrm{g}}, \mathrm{W}_{\mathrm{t} 2}, \mathrm{~W}_{\mathrm{g}}, \mathrm{r}, \mathrm{L}_{1}, \mathrm{~L}_{2}, \mathrm{~W}_{1}$, and $\mathrm{W}_{2}$ are kept constant at $12.5 \mathrm{~mm}, 10.8 \mathrm{~mm}, 1.2 \mathrm{~mm}, 30 \mathrm{~mm}, 7.5 \mathrm{~mm}, 2.5 \mathrm{~mm}, 2.5 \mathrm{~mm}, 3.6$ $\mathrm{mm}$, and $1 \mathrm{~mm}$ respectively. It is clear from the Fig. 4 that as the length of the etched tapper $\left(\mathrm{L}_{\mathrm{t}}\right)$ on the ground plane increases the matching of the impedance band width over the operating impedance band width increases. 


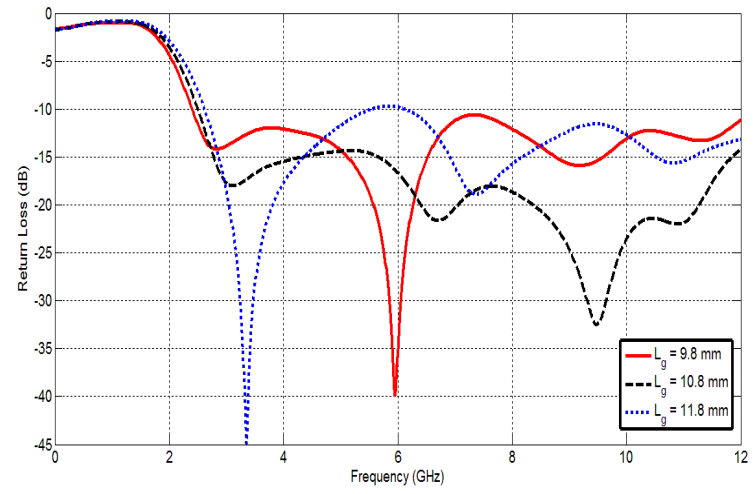

Fig.3. Parametric study of the ground plane length $\left(\mathrm{L}_{\mathrm{g}}\right)$.

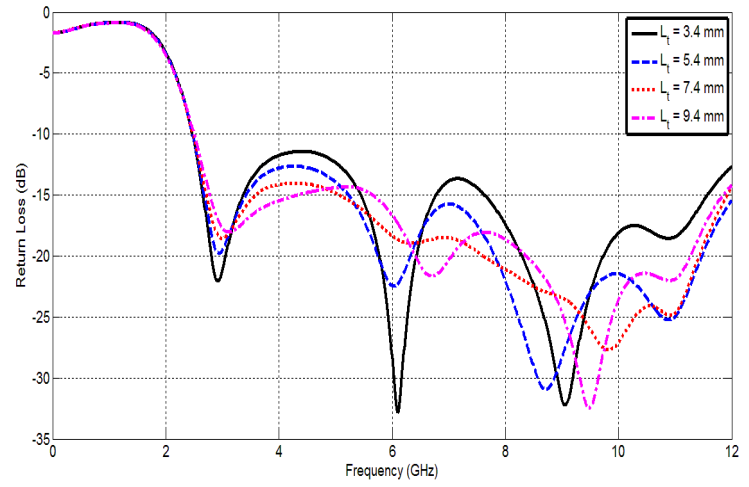

Fig.4. Parametric study of the length of the etched tapper $\left(L_{t}\right)$ on the ground plane.

2.4. Effect of the bottom width of the etched tapper $\left(W_{t 2}\right)$ on the ground plane.

Fig.5 shows investigation of the influence of the bottom width of the etched tapper $\left(\mathrm{W}_{12}\right)$ on the ground plane dimensions. Four values of the bottom width of the etched tapper $\left(\mathrm{W}_{\mathrm{t} 2}\right)$ on the ground plane are assumed $(1.2,1.6,2.4$, and $3.2 \mathrm{~mm})$. The values $\mathrm{L}_{\mathrm{f}}$, $\mathrm{L}_{\mathrm{g}}, \mathrm{L}_{\mathrm{t}}, \mathrm{W}_{\mathrm{g}}, \mathrm{r}, \mathrm{L}_{1}, \mathrm{~L}_{2}, \mathrm{~W}_{1}$, and $\mathrm{W}_{2}$ are kept constant at $12.5 \mathrm{~mm}, 10.8 \mathrm{~mm}, 9.4 \mathrm{~mm}, 30 \mathrm{~mm}$, $7.5 \mathrm{~mm}, 2.5 \mathrm{~mm}, 2.5 \mathrm{~mm}, 3.6 \mathrm{~mm}$, and $1 \mathrm{~mm}$ respectively. It is clear from the Fig. 5 that as the bottom width of the etched tapper $\left(\mathrm{W}_{\mathrm{t} 2}\right)$ on the ground plane increases the matching of the impedance band width over the operating impedance band width decreases.

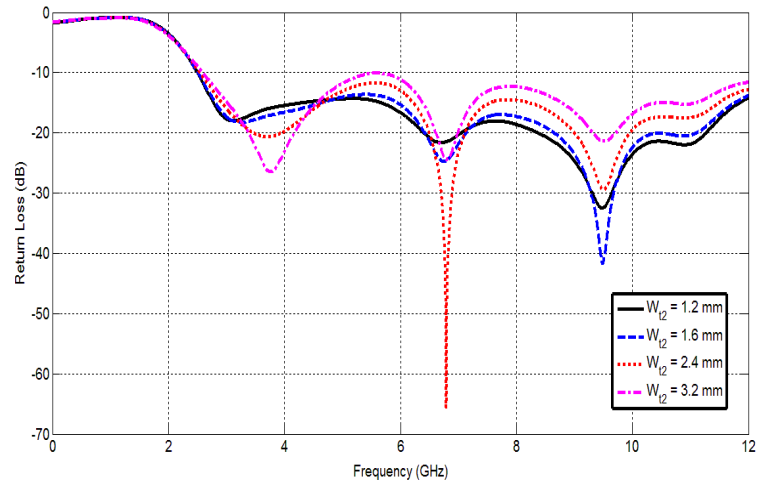

Fig.5. Parametric study of the bottom width of the etched tapper $\left(\mathrm{W}_{\mathrm{t} 2}\right)$ on the ground plane. 


\subsection{Effect of the width of the ground plane $\left(W_{g}\right)$.}

Fig.6 shows investigation of the influence of the width of the ground plane $\left(\mathrm{W}_{\mathrm{g}}\right)$ dimensions. Four values of the width of the ground plane $\left(\mathrm{W}_{\mathrm{g}}\right)$ are assumed $(20,25,30$, and $40 \mathrm{~mm}$ ). The values $\mathrm{L}_{\mathrm{f}}, \mathrm{L}_{\mathrm{g}}, \mathrm{L}_{\mathrm{t}}, \mathrm{W}_{\mathrm{t} 2}, \mathrm{r}, \mathrm{L}_{1}, \mathrm{~L}_{2}, \mathrm{~W}_{1}$, and $\mathrm{W}_{2}$ are kept constant at $12.5 \mathrm{~mm}$, $10.8 \mathrm{~mm}, 9.4 \mathrm{~mm}, 1.2 \mathrm{~mm}, 7.5 \mathrm{~mm}, 2.5 \mathrm{~mm}, 2.5 \mathrm{~mm}, 3.6 \mathrm{~mm}$, and $1 \mathrm{~mm}$ respectively. It is clear from the Fig.6 that as the width of the ground plane increases the matching of the impedance band width over the operating impedance band width increases.

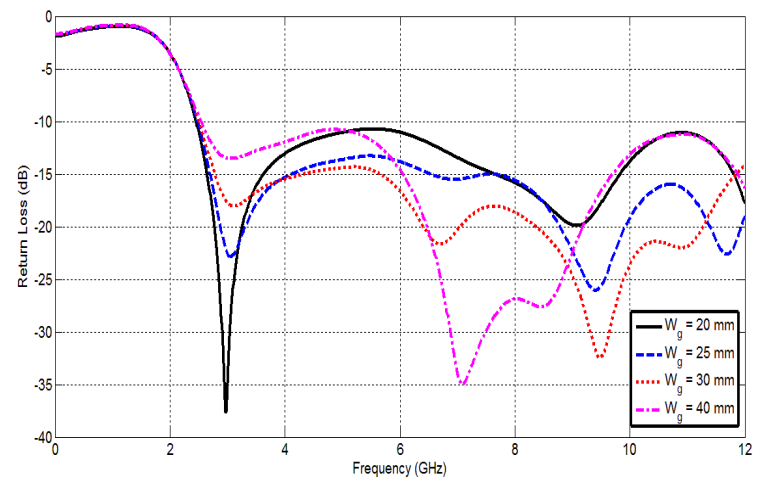

Fig.6. Parametric study of the ground plane width $\left(\mathrm{W}_{\mathrm{g}}\right)$.

\subsection{Effect of the radius of the circular patch antenna (r).}

Fig.7 shows investigation of the influence of the radius of the circular patch antenna (r) dimensions. Four values of the radius of the circular patch antenna (r) are assumed (5.5, 6.5, 7.5, and $9.5 \mathrm{~mm}$ ). The values $\mathrm{L}_{\mathrm{f}}, \mathrm{L}_{\mathrm{g}}, \mathrm{L}_{\mathrm{t}}, \mathrm{W}_{\mathrm{t} 2}, \mathrm{Wg}, \mathrm{L}_{1}, \mathrm{~L}_{2}, \mathrm{~W}_{1}$, and $\mathrm{W}_{2}$ are kept constant at $12.5 \mathrm{~mm}, 10.8 \mathrm{~mm}, 9.4 \mathrm{~mm}, 1.2 \mathrm{~mm}, 30 \mathrm{~mm}, 2.5 \mathrm{~mm}, 2.5 \mathrm{~mm}, 3.6 \mathrm{~mm}$, and $1 \mathrm{~mm}$ respectively. It is clear from the Fig.7 that as the radius of the circular patch antenna (r) increases the matching of the impedance band width over the operating impedance band width increases then decreased.

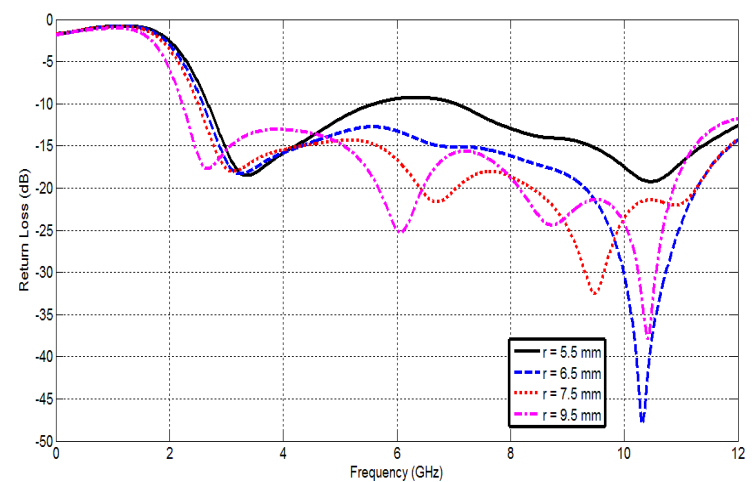

Fig.7. Parametric study of the radius of the circular patch antenna (r).

\subsection{Effect of the first step length for the patch antenna $\left(L_{1}\right)$.}

Fig. 8 shows investigation of the influence of the first step length for the patch antenna $\left(\mathrm{L}_{1}\right)$ dimensions. Three values of the first step length for the patch antenna $\left(\mathrm{L}_{1}\right)$ are assumed $(1.5,2.5$, and $3.5 \mathrm{~mm})$. The values $\mathrm{L}_{\mathrm{f}}, \mathrm{L}_{\mathrm{g}}, \mathrm{L}_{\mathrm{t}}, \mathrm{W}_{\mathrm{t} 2}, \mathrm{Wg}, \mathrm{r}, \mathrm{L}_{2}, \mathrm{~W}_{1}$, and $\mathrm{W}_{2}$ are kept constant at $12.5 \mathrm{~mm}, 10.8 \mathrm{~mm}, 9.4 \mathrm{~mm}, 1.2 \mathrm{~mm}, 30 \mathrm{~mm}, 7.5 \mathrm{~mm}, 2.5 \mathrm{~mm}, 3.6 \mathrm{~mm}$, and $1 \mathrm{~mm}$ 
respectively. It is clear from the Fig.8 that as the first step length for the patch antenna $\left(\mathrm{L}_{1}\right)$ increases the matching of the impedance band width at the lower operating impedance band width decreases and increases at the upper operating impedance band width.

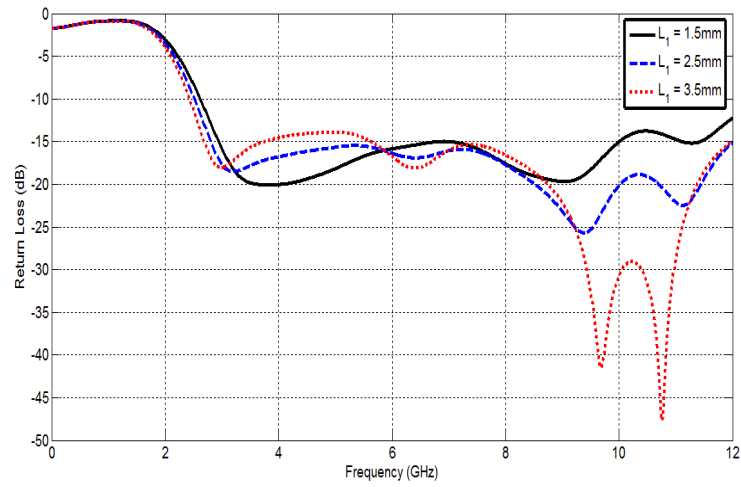

Fig.8. Parametric study of the first step length for the patch antenna $\left(\mathrm{L}_{1}\right)$

\subsection{Effect of the second step length for the patch antenna $\left(L_{2}\right)$.}

Fig.9 shows investigation of the influence of the second step length for the patch antenna $\left(\mathrm{L}_{2}\right)$ dimensions. Three values of the second step length for the patch antenna $\left(\mathrm{L}_{2}\right)$ are assumed $(1.5,2.5$, and $3.5 \mathrm{~mm})$. The values $\mathrm{L}_{\mathrm{f}}, \mathrm{L}_{\mathrm{g}}, \mathrm{L}_{\mathrm{t}}, \mathrm{W}_{\mathrm{t} 2}, \mathrm{Wg}, \mathrm{r}, \mathrm{L}_{1}, \mathrm{~W}_{1}$, and $\mathrm{W}_{2}$ are kept constant at $12.5 \mathrm{~mm}, 10.8 \mathrm{~mm}, 9.4 \mathrm{~mm}, 1.2 \mathrm{~mm}, 30 \mathrm{~mm}, 7.5 \mathrm{~mm}, 2.5 \mathrm{~mm}, 3.6 \mathrm{~mm}$, and $1 \mathrm{~mm}$ respectively. It is clear from the Fig.9 that as the second step length for the patch antenna $\left(\mathrm{L}_{2}\right)$ increases the matching of the impedance band width at the lower operating impedance band width decreases and increases at the upper operating impedance band width.

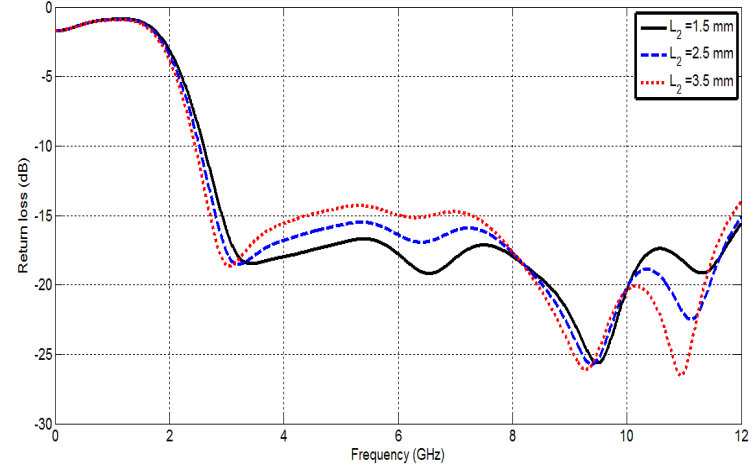

Fig. 9. Parametric study of the second step length for the patch antenna $\left(\mathrm{L}_{2}\right)$

\subsection{Effect of the first step width for the patch antenna $\left(W_{1}\right)$.}

Fig.10 shows investigation of the influence of the first step width for the patch antenna $\left(\mathrm{W}_{1}\right)$ dimensions. Four values of the first step width for the patch antenna $\left(\mathrm{W}_{1}\right)$ are assumed (1.6, 2.6, 3.6 and $4.6 \mathrm{~mm})$. The values $\mathrm{L}_{\mathrm{f}}, \mathrm{L}_{\mathrm{g}}, \mathrm{L}_{\mathrm{t}}, \mathrm{W}_{\mathrm{t} 2}, \mathrm{Wg}, \mathrm{r}, \mathrm{L}_{1}, \mathrm{~L}_{2}$, and $\mathrm{W}_{2}$ are kept constant at $12.5 \mathrm{~mm}, 10.8 \mathrm{~mm}, 9.4 \mathrm{~mm}, 1.2 \mathrm{~mm}, 30 \mathrm{~mm}, 7.5 \mathrm{~mm}, 2.5 \mathrm{~mm}, 2.5 \mathrm{~mm}$, and $1 \mathrm{~mm}$ respectively. It is clear from the Fig. 10 that as the first step width for the patch antenna $\left(\mathrm{W}_{1}\right)$ increases the matching of the impedance band width over all the operating impedance band width increases then it decreases at the center of the operating band width. 


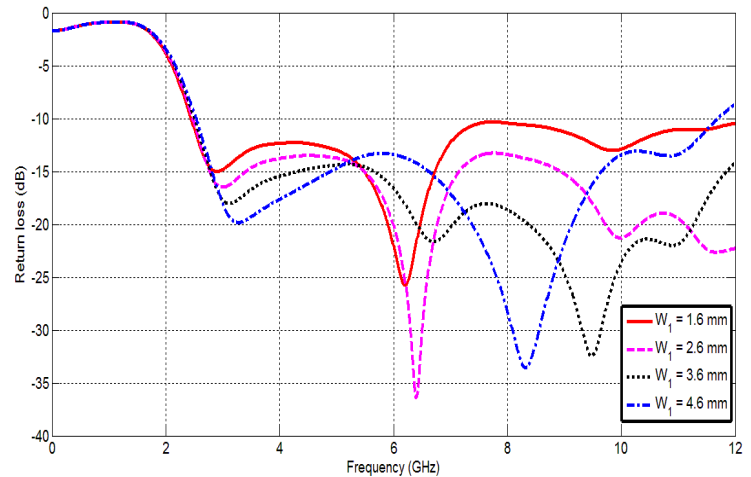

Fig. 10. Parametric study of the first step width for the patch antenna $\left(\mathrm{W}_{1}\right)$

\subsection{0- Effect of the second step length for the patch antenna $\left(W_{2}\right)$.}

Fig.11 shows investigation of the influence of the second step width for the patch antenna $\left(\mathrm{W}_{2}\right)$ dimensions. Four values of the second step width for the patch antenna $\left(\mathrm{W}_{2}\right)$ are assumed $(0.5,1,1.5$, and $2 \mathrm{~mm})$. The values $\mathrm{L}_{\mathrm{f}}, \mathrm{L}_{\mathrm{g}}, \mathrm{L}_{\mathrm{t}}, \mathrm{W}_{\mathrm{t} 2}, \mathrm{Wg}, \mathrm{r}, \mathrm{L}_{1}, \mathrm{~L}_{2}$, and $\mathrm{W}_{1}$ are kept constant at $12.5 \mathrm{~mm}, 10.8 \mathrm{~mm}, 9.4 \mathrm{~mm}, 1.2 \mathrm{~mm}, 30 \mathrm{~mm}, 7.5 \mathrm{~mm}, 2.5 \mathrm{~mm}, 2.5 \mathrm{~mm}$ and $3.6 \mathrm{~mm}$ respectively. It is clear from the Fig. 11 that as the second step width for the patch antenna $\left(\mathrm{W}_{2}\right)$ increases the matching of the impedance band width at the lower operating impedance band width increases and decreases at the upper operating impedance band width.

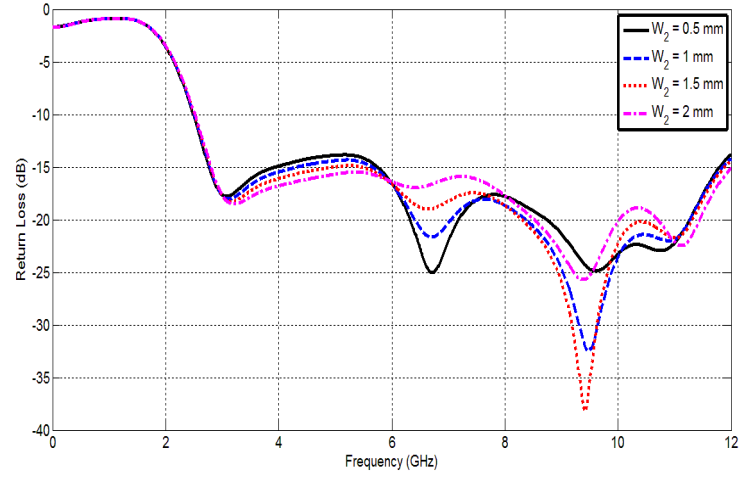

Fig. 11. Parametric study of the second step width for the patch antenna $\left(\mathrm{W}_{2}\right)$

\section{UWB antenna design and configuration}

A proposed design of UWB monopole microstrip antenna is presented. A prototype of the proposed microstrip monopole antenna with optimal design parameters is shown in Fig. 12. The configuration of the proposed antenna consists of a circular patch with two steps, a partial ground plane with tapered trapezoidal defected ground structure (DGS), and a microstrip feedline. The antenna structure is designed on FR4 substrate with dielectric constant of $\varepsilon_{\mathrm{r}}=4.5$, loss tangent 0.025 and substrate thickness of $1.5 \mathrm{~mm}$. The antenna was simulated using CST Microwave studio [8]. The optimized antenna parameters are shown in table 1 . 


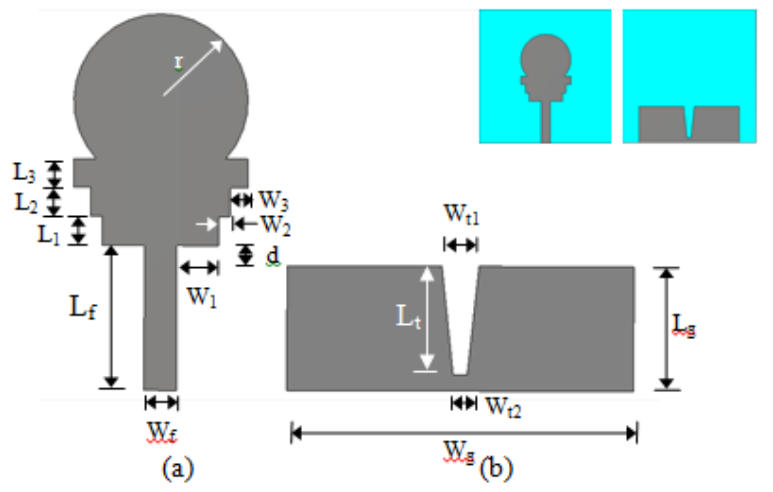

Fig.12. The geometry of the proposed UWB antenna structure:

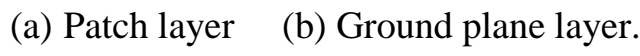

Table 1.

The optimized parameters for the proposed UWB antenna.

\begin{tabular}{|c|c|c|c|c|c|}
\hline Parameter & $\begin{array}{c}\text { Value } \\
(\mathrm{mm})\end{array}$ & Parameter & $\begin{array}{c}\text { Value } \\
(\mathrm{mm})\end{array}$ & Parameter & $\begin{array}{c}\text { Value } \\
(\mathrm{mm})\end{array}$ \\
\hline $\mathrm{L}_{\mathrm{g}}$ & 10.8 & $\mathrm{~L}_{2}$ & 2.5 & $\mathrm{~d}$ & 1.7 \\
\hline $\mathrm{W}_{\mathrm{g}}$ & 30 & $\mathrm{~L}_{3}$ & 2.5 & $\mathrm{~W}_{\mathrm{t} 1}$ & 3.2 \\
\hline $\mathrm{L}_{\mathrm{f}}$ & 12.5 & $\mathrm{~W}_{1}$ & 3.6 & $\mathrm{~W}_{\mathrm{t} 2}$ & 1.2 \\
\hline $\mathrm{W}_{\mathrm{f}}$ & 2.8 & $\mathrm{~W}_{2}$ & 1 & $\mathrm{r}$ & 7.5 \\
\hline $\mathrm{L}_{1}$ & 2.5 & $\mathrm{~W}_{3}$ & 1.5 & $\mathrm{~L}_{\mathrm{t}}$ & 9.4 \\
\hline
\end{tabular}

\section{Results and discussions}

The proposed antenna was designed using CST Microwave studio software package, which utilizes the finite integration technique for electromagnetic computation. Fig. 13 shows the measured and simulated return loss of the proposed antenna. The design is simulated on a machine with core i5 processor and 4GB RAM and took a time of 29 minutes for each run.

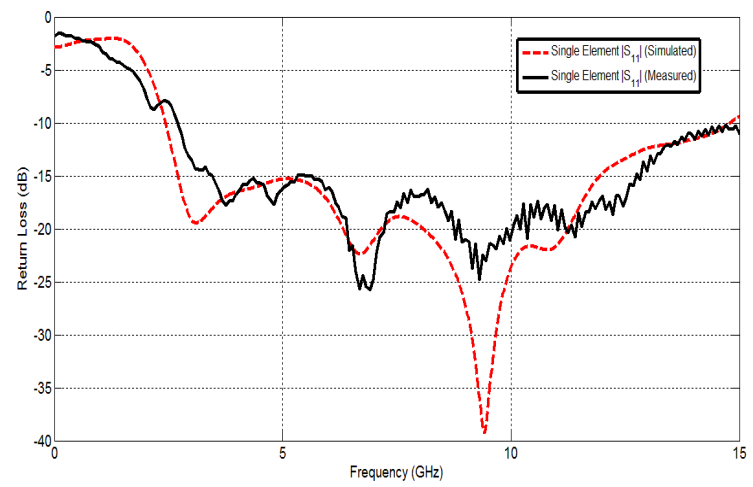

Fig. 13. The measured and simulated return loss of the proposed monopole antenna.

The simulated 10-dB return loss bandwidth is from $2.49 \mathrm{GHz}$ to $14.42 \mathrm{GHz}$ and is from $2.69 \mathrm{GHz}$ to $14.93 \mathrm{GHz}$ for the measured one. The simulated gain and directivity curve 
versus the frequency is shown in Fig. 14. It is seen that the gain has a good level through the high frequency band. Fig. 15 and Fig. 16 show the measured and simulated far-field radiation pattern (E-plane and $\mathrm{H}$-plane) for the proposed antenna at frequencies $3.1 \mathrm{GHz}$ and $5 \mathrm{GHz}$ respectively. Fig. 17 shows the photos of the fabricated antenna connected with the vector network analyzer R\&S Model (ZVB20).

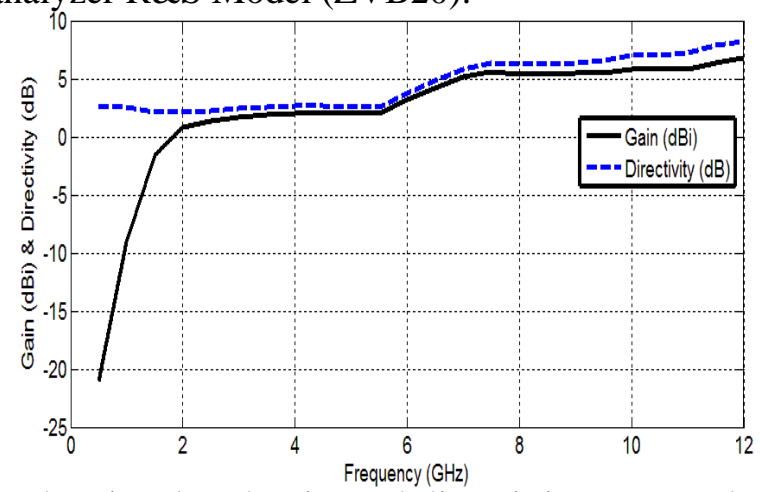

Fig. 14. The simulated gain and directivity versus the frequency.

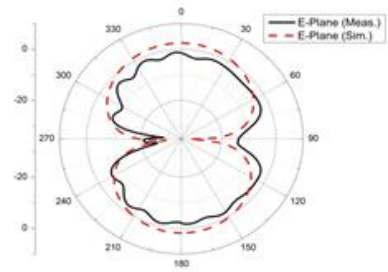

E-plane

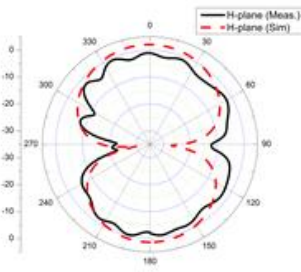

H-plane

Fig. 15. The measured and simulated far-field radiation pattern at frequency $3.3 \mathrm{GHz}$.

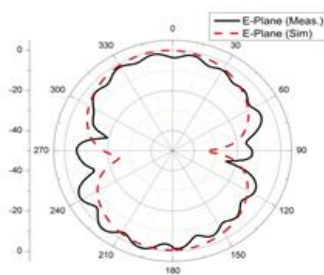

E-plane

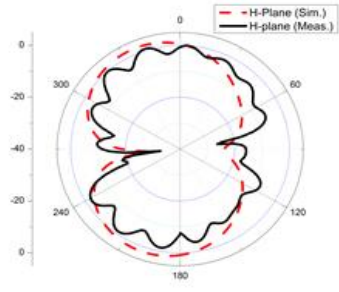

H-plane

Fig. 16. The measured and simulated far-field radiation pattern at frequency $5 \mathrm{GHz}$.

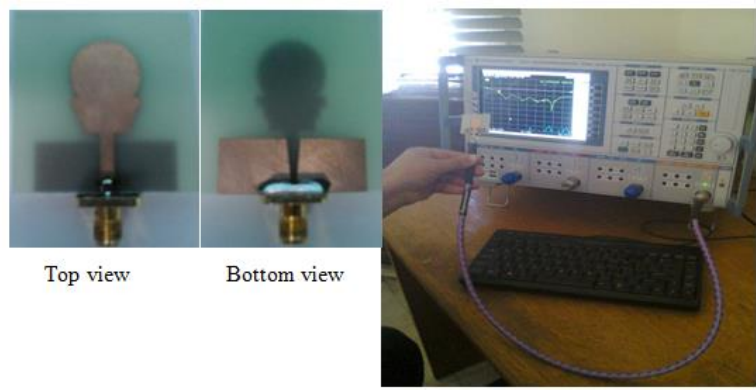

Fig. 17. The fabricated photos of the proposed UWB antenna 


\section{UWB antenna equivalent circuit}

A simplified lumped element circuit model of the UWB patch antenna has been proposed. This model was obtained by studying the scattering parameter $\left(S_{11}\right)$ of the antenna structure by simulating the antenna in CST Microwave Studio. By obtaining this S-parameter the overall structure of the circuit model had been transformed to imply the characteristics of the antenna. The equivalent circuit of patch antenna is shown in Fig. 18 where patch cavity is modeled as a parallel RLC circuit, while the probe inductance is modeled as a series inductor. Fig. 19(a) shows the structure of step discontinuity. The equivalent circuit of the unit of step discontinuity is modeled as Fig. 19(b).

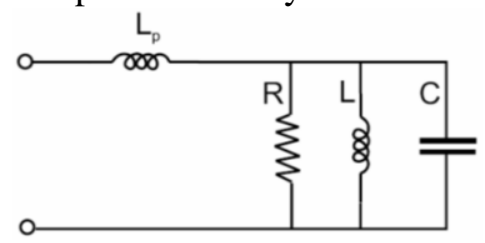

Fig. 18 . Equivalent circuit of patch antenna.

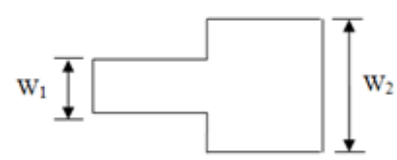

(a)

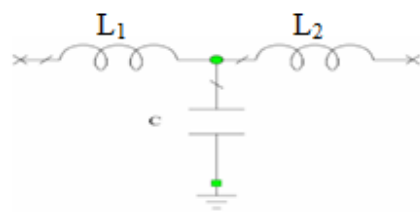

(b)

Fig. 19. (a) Structure of step discontinuity (b) The equivalent circuit of the unit of step discontinuity

Fig. 20 shows the equivalent circuit of UWB circular patch antenna. The proposed antenna is designed by using equivalent circuit of step discontinuity, circular patch antenna. In this model the patch is modeled as a parallel RLC circuit. The circuit model had been simulated using Advanced Design System 2008 (ADS) simulator and the Sparameter is compared with the obtained scattering parameter from simulating the EM structure in CST microwave studio simulator. Fig.21 shows a simulated return loss of the UWB patch antenna compared with the circuit simulator model. Table 2 shows the optimized parameters for the equivalent circuit model of the proposed UWB antenna.

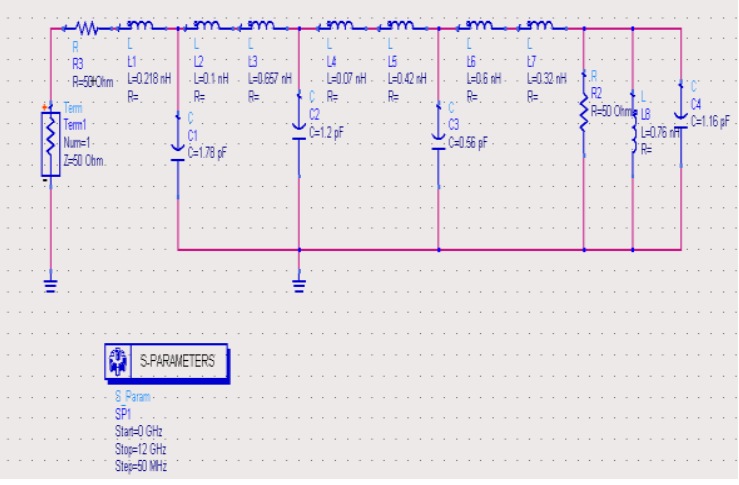

Fig. 20. The equivalent circuit of UWB circular proposed patch antenna 


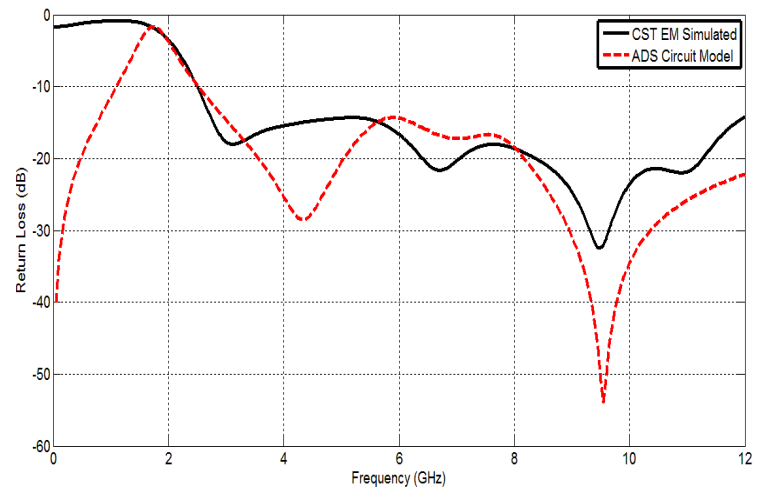

Fig. 21. Simulated return loss of the proposed antenna compared with the circuit simulator model.

\section{Table 2.}

The optimized parameters for the circuit model of the proposed UWB antenna.

\begin{tabular}{|c|c|c|c|c|c|}
\hline Parameter & Value $(\mathrm{nH})$ & Parameter & Value $(\mathrm{nH})$ & Parameter & Value $(\mathrm{pF})$ \\
\hline $\mathrm{L}_{1}$ & 0.218 & $\mathrm{~L}_{5}$ & 0.42 & $\mathrm{C}_{1}$ & 1.78 \\
\hline $\mathrm{L}_{2}$ & 0.1 & $\mathrm{~L}_{6}$ & 0.6 & $\mathrm{C}_{2}$ & 1.2 \\
\hline $\mathrm{L}_{3}$ & 0.657 & $\mathrm{~L}_{7}$ & 0.32 & $\mathrm{C}_{3}$ & 0.56 \\
\hline $\mathrm{L}_{4}$ & 0.07 & $\mathrm{~L}_{8}$ & 0.76 & $\mathrm{C}_{4}$ & 1.16 \\
\hline
\end{tabular}

\section{Modified Wilkinson power divider.}

The design of UWB feeding networks is based on modifying the traditional Wilkinson power divider. Fig. 22 shows the circuit layout of the feeding network for UWB operation [10]. As shown from Fig. 22, it composed of a modified one- section Wilkinson power divider which has characteristic impedance of $Z_{1}$ and electrical length $\theta_{1}$. For broadening the bandwidth a stub matching network is added to each branch with additional transmission line at the end of the stage. By other word, an extended transmission line with parameters $\left(\mathrm{Z}_{1}, \theta_{1}^{z}\right)$ and an open circuit stub $(\mathrm{OC})$ with parameters $\left(\mathrm{Z}_{\mathrm{s}}, \theta_{\mathrm{s}}\right)$ have been added to each branch. The two aforementioned sections are connected to another section of Wilkinson power divider with transmission line of $\left(\mathrm{Z}_{2}, \theta_{2}\right)$ at the end of the stub matching network. By adjusting the length and width of the OC stubs, the bandwidth can be broadened.

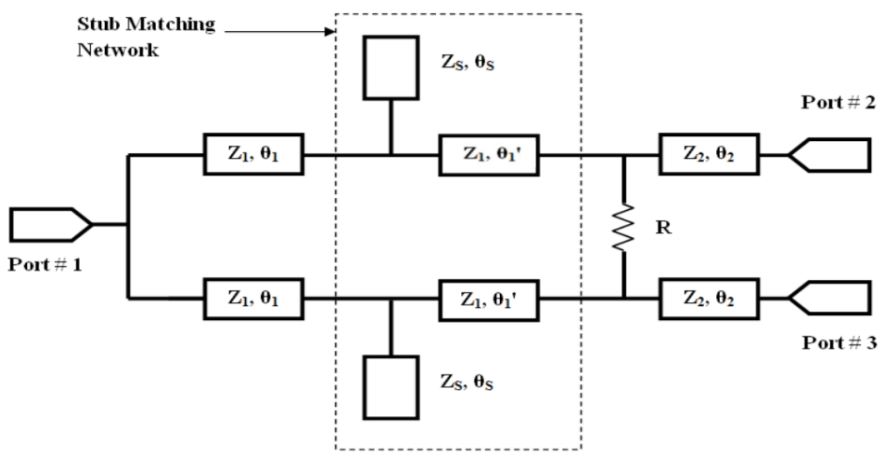

Fig. 22. The circuit layout of the proposed feeding network for UWB operation [10]. 
First, a conventional Wilkinson power divider is designed with its center frequency $f_{0}=$ $6.85 \mathrm{GHz}$ and bandwidth ratio $\left(f_{\mathrm{U}} / f_{\mathrm{L}}\right)$ equal 3.42 for covering the whole UWB frequency range (3.1-10.6 GHz). It is shown from Fig. 22 that it consists of a modified two-section Wilkinson power divider in [8] with removing the resistor of the second section $R_{2}$. The input and output impedance are chosen to be $50 \Omega$. Only one resistor is placed between the output ports to prevent the signal transmission and obtain a good isolation between them. According to the desired bandwidth ratio $\left(m=f_{\mathrm{U}} / f_{\mathrm{L}}\right)$ the initial values for the divider parameters $\mathrm{Z}_{1}, \theta_{1}, \mathrm{Z}_{2}, \theta_{2}$ and $\mathrm{B}_{\mathrm{s}}$ can be determined by means of elementary transmission line theory [9]. Then the length of the extended line is chosen arbitrarily to be different than that of the main line $\left(\theta_{1}^{\prime} \neq \theta_{1}\right)$ to obtain more flexibility and degree of freedom and hence the bandwidth can be enhanced. In order to get the values of $Z_{1}, Z_{2}, Z_{s}, \theta_{1}, \theta_{2}, \theta_{1}^{s}$ and $B_{s}$ an even mode and odd mode analysis is derived in $[4,9,10,11]$ with removing the resistor of the second section $R_{2}$ using equations (1-5). The initial value of $\theta_{1}$ can be calculated according to the operating bandwidth from equation (1) [9]:

$$
\begin{aligned}
& \theta_{1}=90^{\circ}\left[1-\frac{1}{\sqrt{2}}\left(\frac{f_{u} / f_{l}-1}{f_{u} / f_{1}+1}\right)\right] \\
& Z_{2}=Z_{0} \sqrt{\frac{1}{2 \alpha}+\sqrt{\frac{1}{4 \alpha^{2}}+2}} \\
& Z_{1}=\frac{2 z_{0}^{2}}{z_{2}} \\
& \alpha=\left(\tan \left(\theta_{1}\right)^{2}=\left[\tan \left(\beta_{1} \cdot \frac{n \pi}{\beta_{1}(1+m)}\right)\right]^{2}=\left[\tan \left(\frac{n \pi}{(1+m)}\right)\right]^{2}\right. \\
& \mathrm{n}=1 \text { the frequency ratio between }(1<\mathrm{m}<3) \\
& B_{s}=\left(1-\tan \left(\theta_{1}\right) \tan \left(\theta_{1}^{\prime}\right)\right) /\left(Z_{1} \tan \left(\theta_{1}\right)\right)=\tan \theta_{s} / Z_{s} \\
& Z_{s}=\left(Z_{1} \tan \left(\theta_{1}\right) \tan \left(\theta_{s}\right)\right) /\left(1-\tan \left(\theta_{1}\right) \tan \left(\theta_{1}^{\prime}\right)\right)
\end{aligned}
$$

\section{Single and double stage modified Wilkinson power divider.}

The initial investigations of the proposed UWB feed network parameters were made from summarized table 3. The proposed UWB feed network is designed on FR4 substrate with dielectric substrate $\varepsilon_{\mathrm{r}}=4.5$ and substrate height $=1.5 \mathrm{~mm}$. The overall size of proposed UWB feed network is $23 \times 19.5 \mathrm{~mm}^{2}$. The parameters of the proposed feed network were optimized using CST-Microwave Studio to obtain a good reflection coefficient at all ports and good isolation over the whole UWB frequency range. The final dimension of the optimized parameters for the proposed feeding network is summarized in table 4 .

\section{Table 3.}

The initial parameters of the proposed UWB feed network

\begin{tabular}{|l|c|c|c|c|c|c|c|}
\hline Parameter & $\mathrm{Z}_{1}$ & $\theta_{1}$ & $\theta_{1}^{\prime}$ & $\mathrm{Z}_{2}$ & $\theta_{2}$ & $\mathrm{Z}_{\mathrm{s}}$ & $\theta_{\mathrm{s}}$ \\
\hline Value & $89 \Omega$ & $48.76^{\mathrm{o}}$ & $27.1^{\mathrm{o}}$ & $61 \Omega$ & $137^{\mathrm{o}}$ & $52.1 \Omega$ & $11.2^{\mathrm{o}}$ \\
\hline
\end{tabular}




\section{Table 4.}

The optimized parameters of the proposed UWB feeding network.

\begin{tabular}{|l|c|c|c|c|c|c|c|}
\hline Parameter & $\mathrm{W}_{1}$ & $L_{1}$ & $L_{1}^{v}$ & $\mathrm{~W}_{2}$ & $L_{2}$ & $\mathrm{~W}_{\mathrm{s}}$ & $L_{\mathrm{s}}$ \\
\hline Value $(\mathrm{mm})$ & 0.67 & 2.18 & 2.015 & 1.98 & 10.12 & 2.63 & 0.55 \\
\hline
\end{tabular}

The measured and simulated return loss at the input port $\left(S_{11}\right)$ in addition to, the isolation between the output ports $\left(S_{23}\right)$ for the proposed feed network is shown in Fig. 23. Fig. 24 shows the measured and simulated power division ratio at the output ports $\left(\mathrm{S}_{21}\right.$, $\mathrm{S}_{31}$ ). The return loss at the input port is reaches to $-40.45 \mathrm{~dB}$ at the middle of the interesting band and it reaches to $11.5 \mathrm{~dB}$ at the end of the band. The return losses at the output ports reach to- $12.5 \mathrm{~dB}$ at the frequency $8 \mathrm{GHz}$ and reaches to $-40 \mathrm{~dB}$ at the end of the band. It can be seen that the power is divided equally between the output ports. The isolation between the two outputs ports $\left(S_{23}=S_{32}\right)$ better than $12.8 \mathrm{~dB}$ at the start of the interesting band $(3.1 \mathrm{GHz})$ and better than $15.8 \mathrm{~dB}$ throughout the other frequency range.
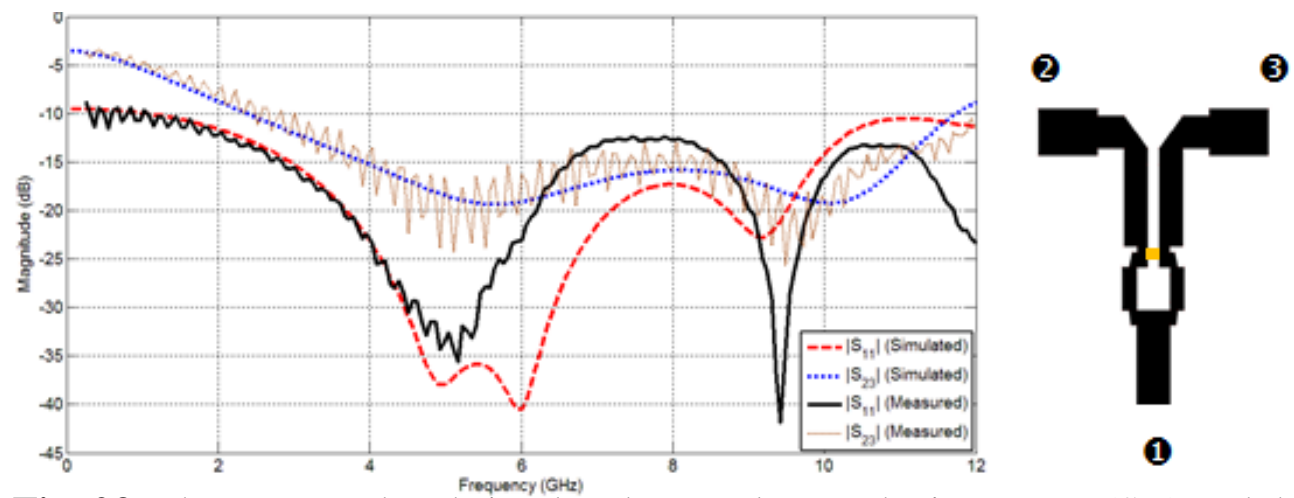

Fig. 23. The measured and simulated return loss at the input port $\left(S_{11}\right)$ and the isolation between the output ports $\left(\mathrm{S}_{23}\right)$.

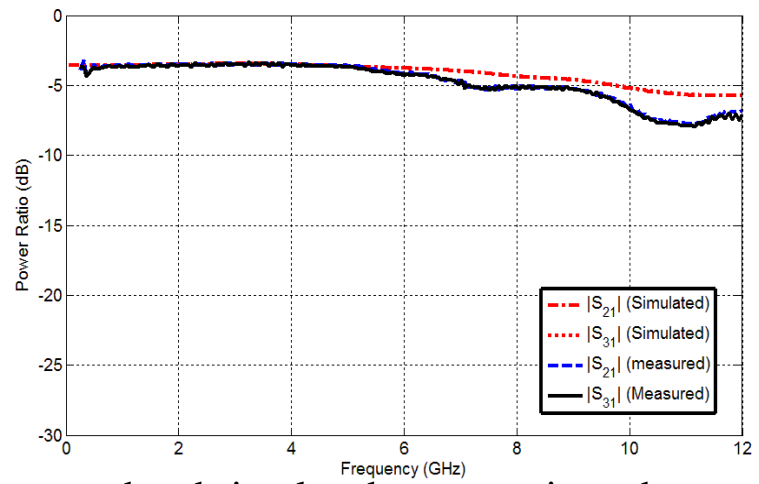

Fig. 24. The measured and simulated power ratio at the output ports $\left(S_{21}, S_{31}\right)$.

As shown from Fig. 24 the values of measured and simulated power ratio at the output ports $\left(S_{21}\right.$ and $\left.S_{31}\right)$ are equal at the same frequency over the all range of frequencies. However, these values $\left(S_{21}\right.$ and $\left.S_{31}\right)$ at the start of frequency range are different from that at the end of frequency range due to the use of FR4 material where the losses increased with the increase the frequency. Fig. 25 shows the measured and simulated return loss at the output ports $\left(\mathrm{S}_{22}, \mathrm{~S}_{33}\right)$. Two Cascaded Modified Wilkinson power Divider is shown in Fig. 26. The two cascaded modified WPD are used to excite $4 \times 1$ linear UWB antenna array. 
The separating distance $\left(\mathrm{d}_{1}=35 \mathrm{~mm}\right)$ between the each adjacent output port is assigned to suitable to connect with the input microstrip transmission line of the UWB antenna array. The simulated return loss at the input port $\left(S_{11}\right)$ and the isolation between the output ports $\left(\mathrm{S}_{23}, \mathrm{~S}_{34}, \mathrm{~S}_{45}\right)$ for the two cascaded modified Wilkinson power divider are shown in Fig. 27. Fig. 28 shows the simulated return loss at the output ports $\left(S_{22}, S_{33}, S_{44}\right.$, and $\left.S_{55}\right)$ for two cascaded modified Wilkinson power divider. Fig. 29 shows the power ratios at the output ports $\left(S_{21}, S_{31}, S_{41}\right.$, and $\left.S_{51}\right)$ for two cascaded modified Wilkinson power divider. Also, , the difference between values of power ratios at the output ports $\left(S_{21}, S_{31}, S_{41}\right.$, and $\left.S_{51}\right)$ at the start of frequency range than that at the end of frequency range due to the use of FR4 material where the losses increased with the increase the frequency.

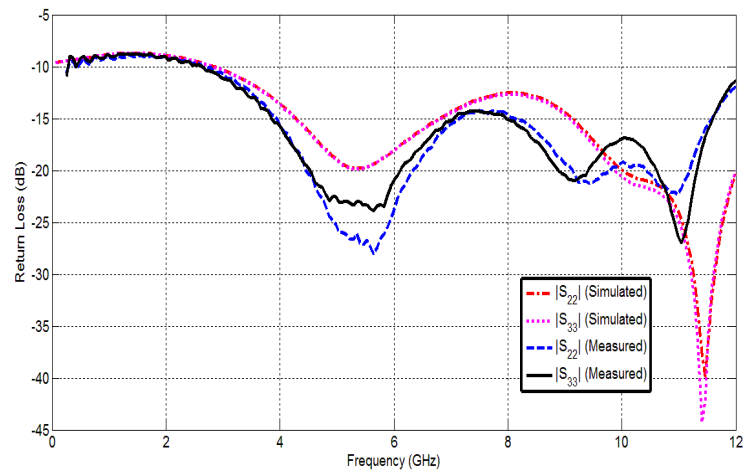

Fig. 25. The measured and simulated return loss at the output ports $\left(S_{22}, S_{33}\right)$.

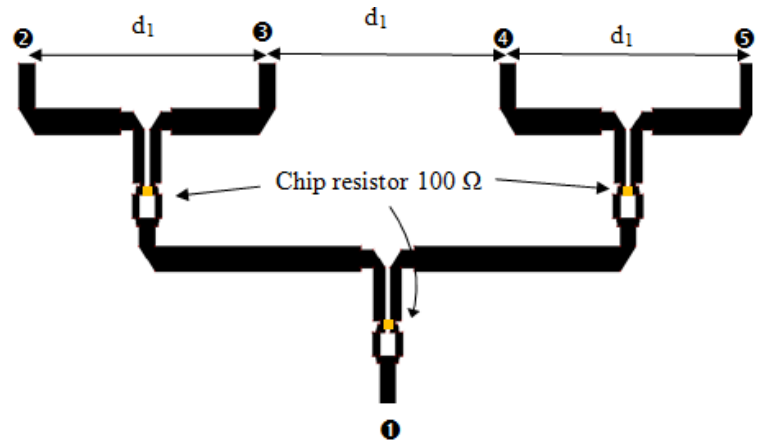

Fig. 26. Two Cascaded Modified Wilkinson power Divider

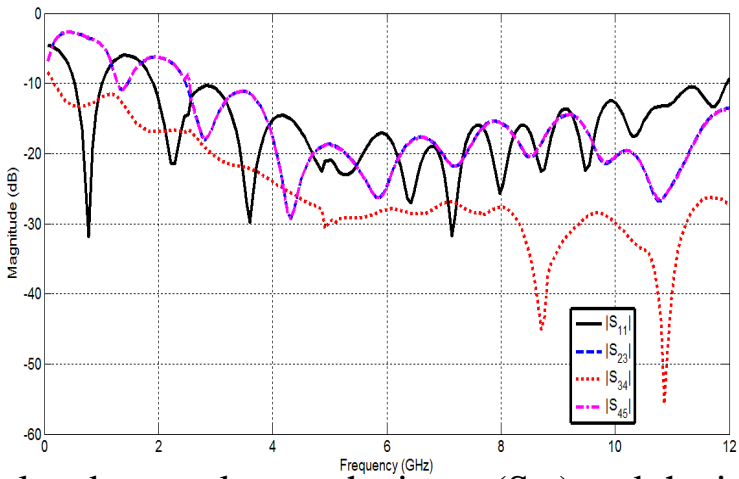

Fig. 27. The simulated return loss at the input $\left(\mathrm{S}_{11}\right)$ and the isolation between the output ports $\left(\mathrm{S}_{23}, \mathrm{~S}_{34}, \mathrm{~S}_{45}\right)$ for two cascaded modified Wilkinson power divider. 


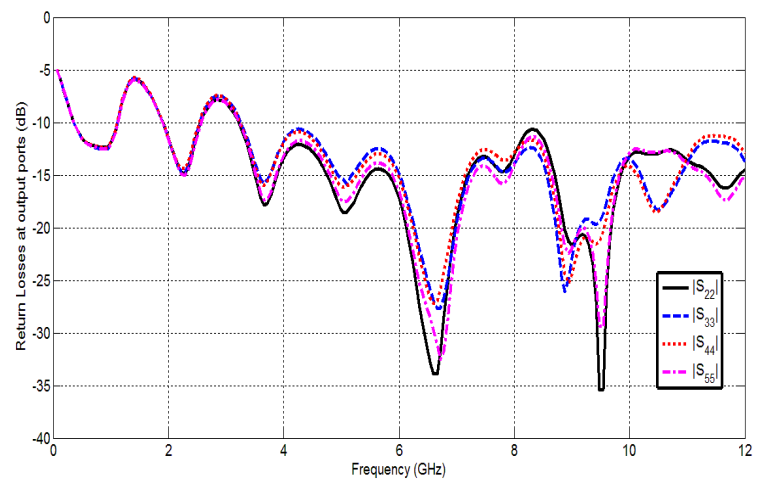

Fig. 28. The simulated return loss at the output ports $\left(\mathrm{S}_{22}, \mathrm{~S}_{33}, \mathrm{~S}_{44}\right.$, and $\left.\mathrm{S}_{55}\right)$ for two cascaded modified Wilkinson power divider.

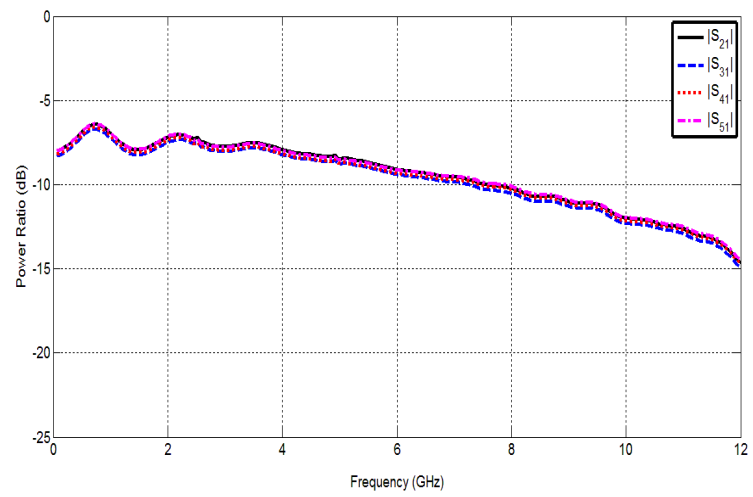

Fig. 29. The simulated power ratios at the output ports (S21, S31, S41, S51) for two cascaded modified Wilkinson power divider.

\section{Two element ultra-wide band linear antenna array}

The two-element UWB linear antenna arrays is composed of UWB feed network circuit which is previously designed and two UWB antenna elements. The geometry of the proposed two-element linear antenna array prototypes is shown in Fig. 30. The spacing between the antenna elements has a great effect on the overall performance of the array where the optimized value is $35 \mathrm{~mm}$. Two UWB antennas without power divider circuit have been studied in order to show the effect of the distance between the antennas. Fig. 31 (a-c) shows the simulated return loss at the input of the two antennas and the coupling between the antenna elements. The target here is to design a two-element linear antenna arrays with good impedance matching characteristics across the desired UWB frequency range. Moreover, the designed arrays should obtain higher gain, and stable radiation patterns throughout the desired frequency band of interest. It has been found from the parametric studies that using a rectangular cut in the common ground plane of dimensions $\left(\mathrm{W}_{\mathrm{g}}\right.$ and $\left.\mathrm{Lg}_{\mathrm{g}}\right)$ in the two-element antenna array, the impedance matching of the antenna array is enhanced through the UWB frequency range. This rectangular cut reduces the mutual coupling between the two antenna elements. The optimized values for the rectangular cut in the common ground plane are: $\mathrm{W}_{\mathrm{g}}=5 \mathrm{~mm}$ and $\mathrm{L}_{\mathrm{g}}=10.8 \mathrm{~mm}$. The interspacing distance between the two antenna effects on the impedance matching characteristic of the antenna and the grating lobe. The larger inter-element spacing, the higher grating lobe will be occurred. The smaller inter-element spacing, the mutual coupling between the two elements is increased as shown in Fig. 20. In case of $d_{1}=30 \mathrm{~mm}$ the two ground 
planes of the two adjacent antennas are stuck (no rectangular cut between the two ground planes) which is cause the coupling between them.

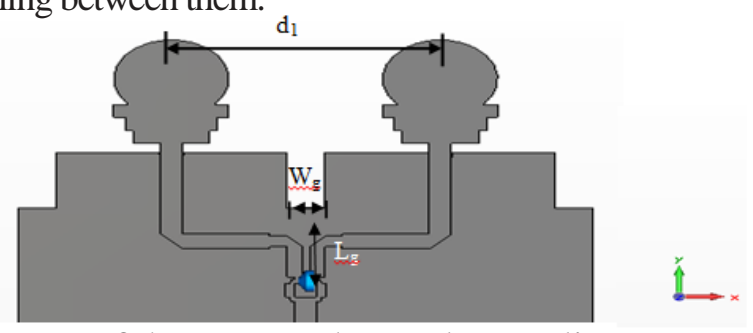

Fig. 30. The geometry of the proposed two-element linear antenna array prototypes

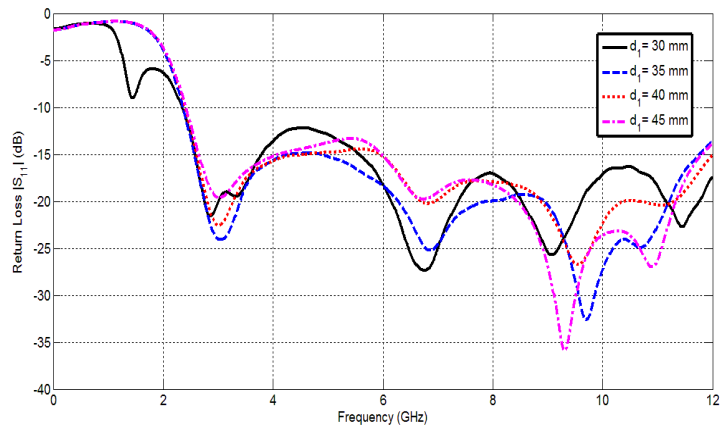

(a)

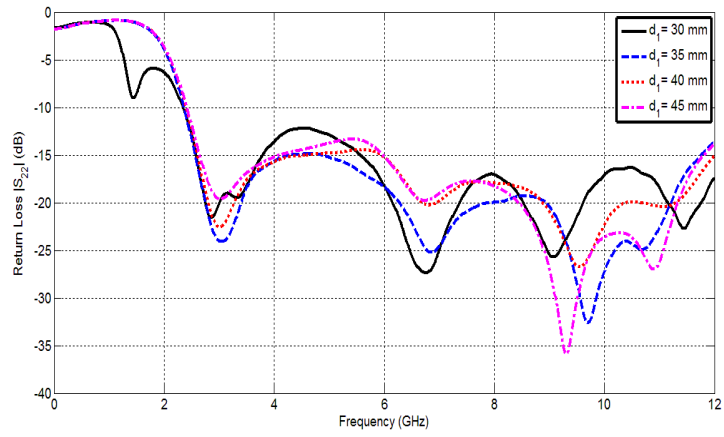

(b)

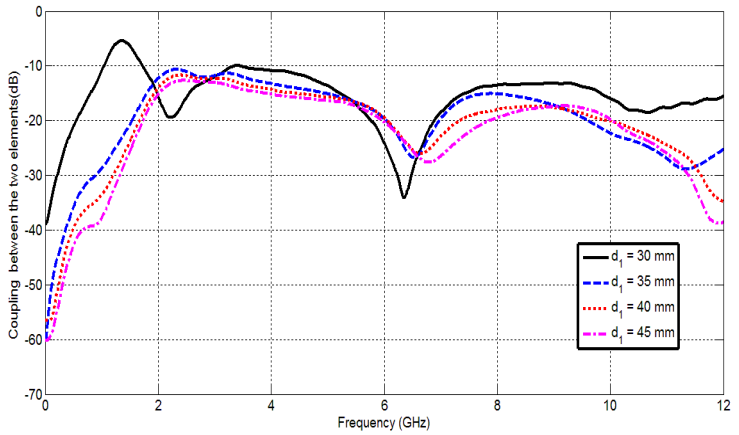

(c)

Fig. 31. The simulated return losses at the two antenna input ports: (a) $S_{11}$ and (b) $\mathrm{S}_{22}$ (c) The coupling between the two antenna elements at different distance values $\left(\mathrm{S}_{21}\right)$. 
The measured and simulated return loss curve for two elements antenna array connected with its power divider circuit are shown in Fig. 32. Fig. 33 shows the gain and the directivity curves over the interesting bands of frequency. Fig. 34 shows the measured and simulated far-field radiation pattern (E- plane and H-plane) at different values of frequency $(3.3 \mathrm{GHz}$ and $5 \mathrm{GHz})$. The matching at frequency equal $3.3 \mathrm{GHz}$ is $-11 \mathrm{~dB}$ and at frequency $5 \mathrm{GHz}$ is $-35 \mathrm{~dB}$.

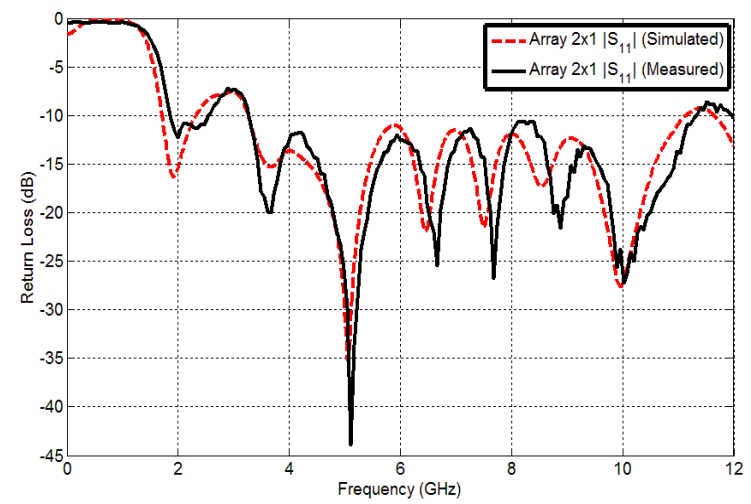

Fig. 32. The measured and simulated return loss for two elements antenna array connected with its power divider circuit.

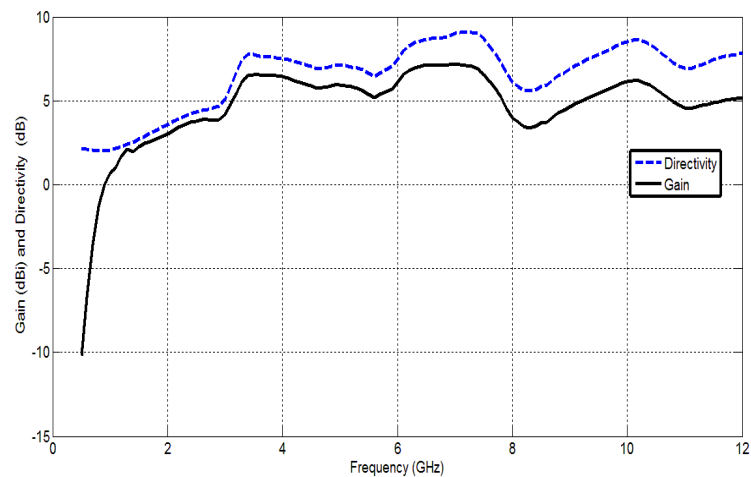

Fig. 33. The simulated gain and the directivity curves over the UWB frequency range.

\section{Four elements ultra-wide band antenna array.}

The four-element UWB linear antenna arrays is composed of UWB feed network circuit which is previously designed and four UWB antenna elements. The geometry of the proposed four-element linear antenna array prototypes is shown in Fig. 35. The target is to design four-element linear antenna arrays with good impedance matching characteristics across the desired UWB frequency range.

The measured and simulated return loss for four elements antenna array connected with its power divider circuit is shown in Fig. 36. Fig. 37 shows the gain and the directivity curves over the interesting bands of frequency where the target of using array is to increase the gain. Fig. 38 shows the measured and simulated far-field radiation pattern (E- plane and H-plane) at different values of frequency. It is clear from Fig. 38 that the beam is more directive in the plane where the linear array is placed $(\mathrm{Phi}=0)$. Fig. 39 shows the fabricated photos of the proposed $4 \times 1$ UWB linear antenna array. 


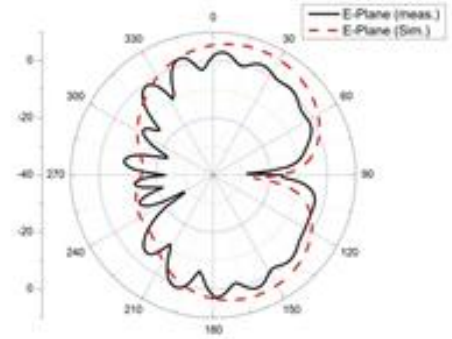

E-plane

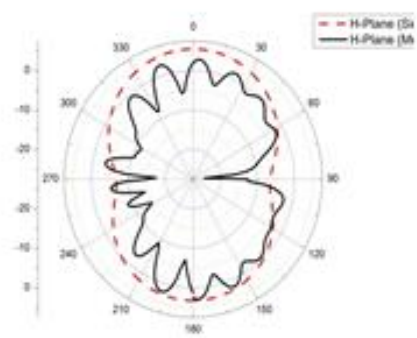

H-plane

(a)

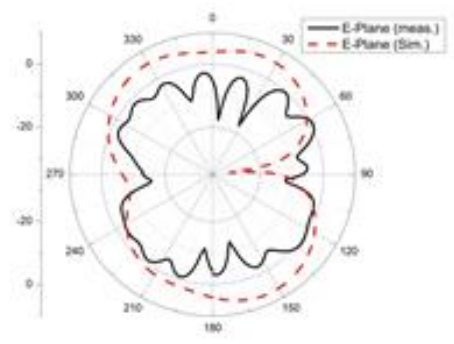

E-plane

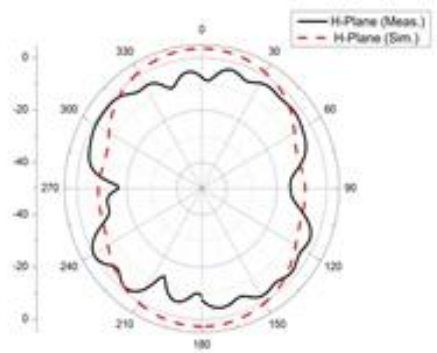

H-plane

(b)

Fig. 34. The measured and simulated far-field radiation pattern (E- and $\mathrm{H}-$ planes) at: (a) $\mathrm{f}=3.3 \mathrm{GHz}$ (b) $\mathrm{f}=5 \mathrm{GHz}$.

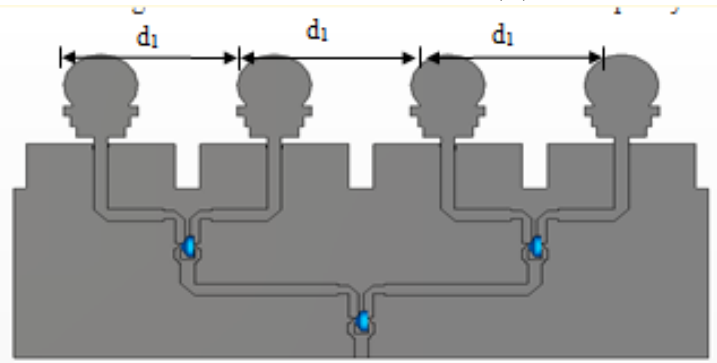

Fig. 35. The geometry of the proposed four-elements linear antenna array prototypes.

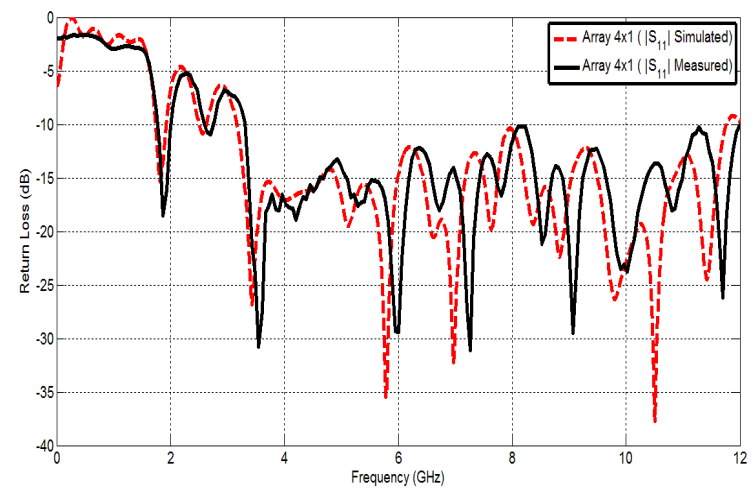

Fig. 36. The measured and simulated return loss for four elements antenna array connected with its power divider circuit. 


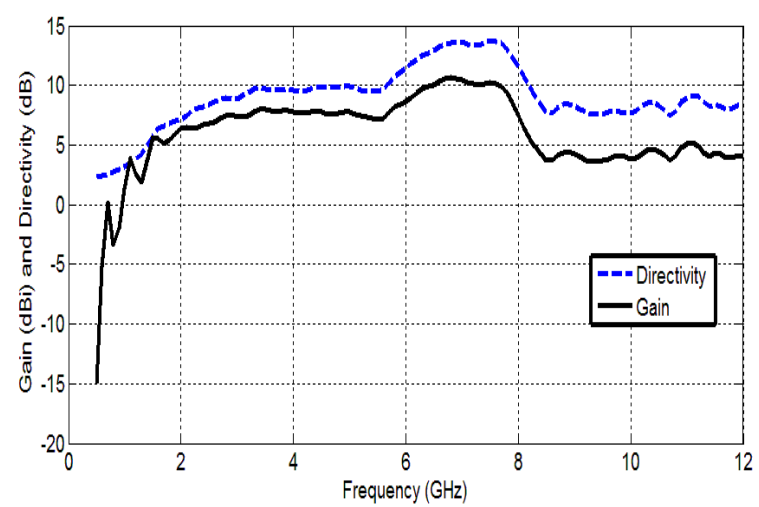

Fig. 37. The simulated gain and the directivity curves over the UWB frequency range.

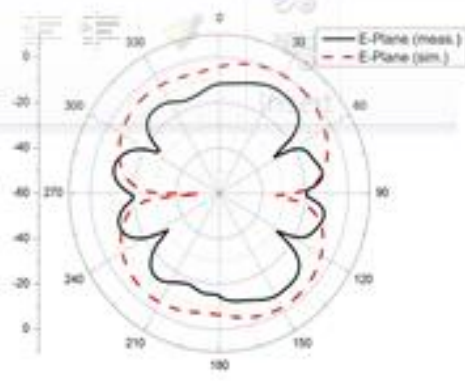

E-plane

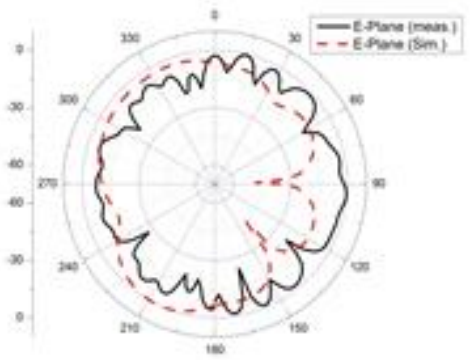

E-plane

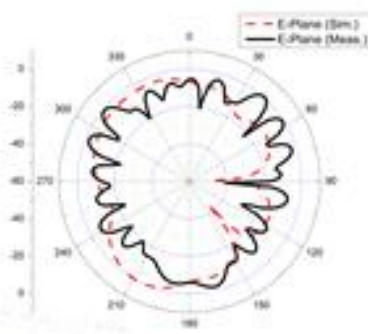

E-plane

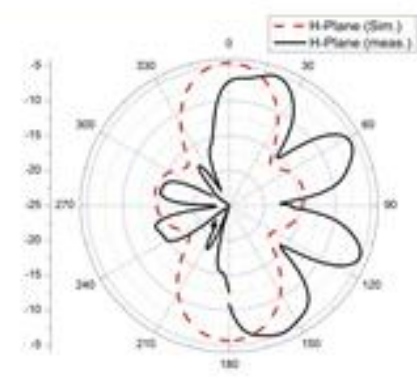

H-plane

(a)

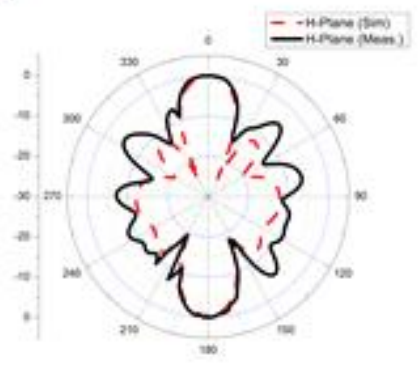

(b)

H-plane

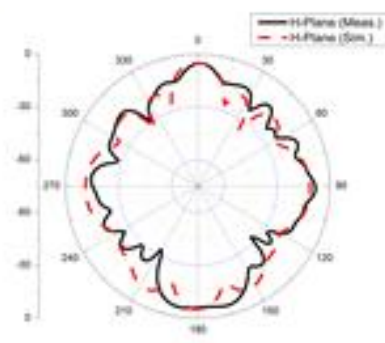

H-plane

(c)

Fig. 38. The measured and simulated far-field radiation pattern (E- plane and $\mathrm{H}$ plane) at: (a) $\mathrm{f}=3.35 \mathrm{GHz}$

(b) $\mathrm{f}=7 \mathrm{GHz}$

(c) $\mathrm{f}=10 \mathrm{GHz}$ 

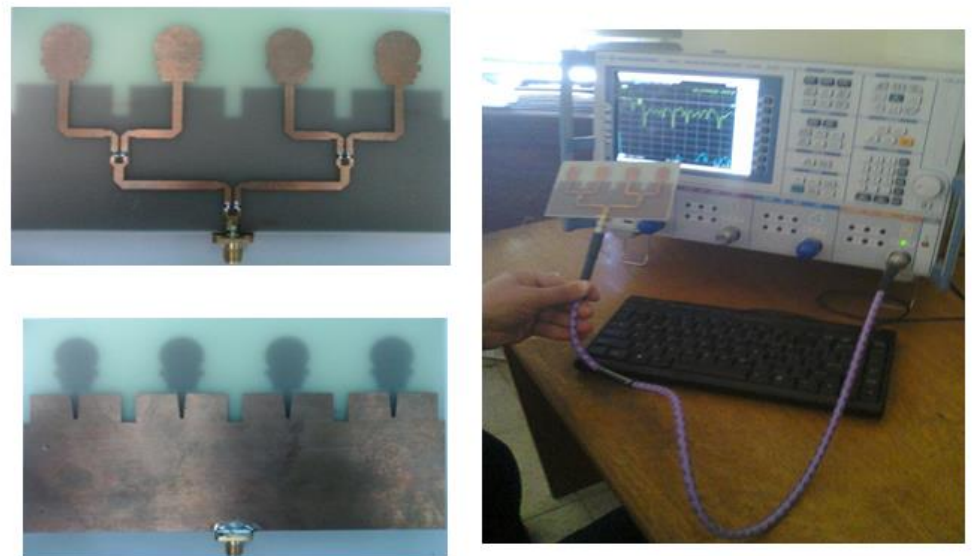

Fig. 39. The fabricated photos of the proposed $4 \times 1$ UWB linear antenna array.

\section{Conclusion}

A small UWB proposed monopole antenna with partial ground plane used for UWB communication systems has been investigated. A prototype with the optimal parameters and its electrical performance has been examined. The antenna demonstrates an ultra-wide impedance bandwidth prototype with satisfactory radiation patterns. An ultra-wideband antenna is operated with $3.1-12 \mathrm{GHz}$ frequency range and size of $40 \times 40 \mathrm{~mm}^{2}$. In addition, a circuit modeling of UWB proposed antenna has been modeled. Moreover, a compatible lumped-elements used in the equivalent circuit modeling for the proposed monopole antenna is established using the Advanced Design System (ADS) software. A good agreement between the simulated return loss using CST- Microwave Studio and the return loss of the proposed equivalent circuit model for the proposed monopole antenna has been obtained. The simulated results of the proposed antenna satisfy the 10-dB return loss requirement for UWB as defined by the FCC. An UWB feeding network circuit has been designed / simulated in order to be used for exciting $2 \times 1$ and $4 \times 1$ linear antenna array. The simulated results for the proposed feed network has a good return loss, isolation and power division ratio at all ports within the whole UWB frequency range. Two- and four-element UWB linear antenna arrays are presented. The average gain for the two-element antenna array is about $5.3 \mathrm{dBi}$ and reaches to $7.15 \mathrm{dBi}$ for the four-element antenna array, over the whole UWB frequency range. A good agreement between the measured and the simulated results of four-element antenna array is appeared. In addition, the simulated and the measured radiation patterns of the antenna element and arrays are introduced.

\section{REFERENCES}

[1] Barrett, W. Terence, "History of Ultra Wideband Communications and Radar: Part I, UWB Communications", Microwave Journal, January $1^{\text {st }}, 2001$.

[2] FCC, "First report and order, revision of part 15 of the commission's rules regarding ultrawideband transmission systems FCC," 2002.

[3] E. J. Wilkinson, "An N-way hybrid power divider," IEEE Trans. Microw. Theory Tech., vol.8, No. 1, pp. 116-118, Jan. 1960.

[4] Ahmed, O. and A. R. Sebak, "A modified Wilkinson power divider/combiner for ultrawideband communications," IEEE Antennas and Propagation Society International Symposium, 1-4, 2009. 
[5] M. E. Bialkowski and A. M. Abbosh, "Design of a Compact UWB Out of-Phase Power Divider," IEEE Microw. Wireless Compon. Lett., vol. 17, No. 4, pp. 289-291, Apr. 2007.

[6] Yang, L. and Q.-X. Chu, "Design of a compact UWB Wilkinson power divider," International Conference on Microwave and Millimeter Wave Technology (ICMMT), Vol. 1, 360-362, 2008.

[7] Lin, Z. and Q.-X. Chu, 'A novel compact UWB power divider for spatial power combining," Journal of Electromagnetic Waves and Applications, Vol. 23, No. 13, 1803-1812, 2009.

[8] CST Microwave Studio Electromagnetic Field Simulation Soft-ware, Computer Simulation Technology, Darmstadt, Germany. Progress In Electromagnetics Research C, Vol. 25, 2012.

[9] Zhou, B., H. Wang, and W.-X. Sheng, "A modified UWB Wilkin-son power divider using delta stub," Progress In Electromagnetics Research Letters, Vol. 19, pp 49-55, 2010.

[10] R. Pazoki, M. R. Ghafouri Fard and H. Ghafouri Fard, "A Modification in the Single-Stage Wilkinson Power Divider to Obtain Wider Bandwidth," Proc. Asia-Pacific Microw, Conf., pp. 2325-2328, Dec. 2007.

[11] X.-P. Ou and Q.-X. Chu, "A Modified Two-section UWB Wilkinson Power Divider", International Conference on Microwave and Millimeter Wave Technology ( ICMMT), China, vol.3, pp.1258-1260,April 21-29,2008.

[12] Sadat, S., M. Fardis, F. G. Gharakhili, and G. R. Dadashzadeh,"A compact microstrip square-ring slot antenna for UWB applications," Progress In Electromagnetics Research, Vol. 67, 173-179, 2007.

[13] Fallahi, R., A. A. Kalteh, and M. G. Roozbahani, "A novel UWB elliptical slot antenna with band-notched characteristics, "Progress In Electromagnetics Research, Vol. 82, 127-136, 2008.

[14] Yin, X.-C., C.-L. Ruan, C.-Y. Ding, and J.-H. Chu, "A planar U type monopole antenna for UWB applications," Progress In Electromagnetics Research Letters, Vol. 2, 1-10, 2008.

[15] Wang, H., H. Zhang, X. Liu, and K. Huang, "A CPW-FED ultra-wideband planar inverted cone antenna," Progress In Electromagnetics Research C, Vol. 12, 101-112, 2010.

[16] Kumar, M., A. Basu, and S. K. Koul, "UWB printed slot antenna with improved performance in time and frequency domains,"Progress In Electromagnetics Research C, Vol. 18, 197-210, 2011.

[17] Li, P., J. Liang, X. Chen, and C. Parini, "A 4-element ultra-wideband tapered- slot-fed antenna array," IEEE Antennas and Propagation Society International Symposium, 44754478, Jul. 9-14, 2006.

[18] S̈̈orgel, W., C. Sturm, and W. Wiesbeck, "Impulse responses of linear UWB antenna arrays and the application to beam steering,"Proc. IEEE International Conference on Ultrawideband, 275-280,Sep. 2005.

[19] Liao, C.-H., P. Hsu, and D.-C. Chang, "Side lobe control of UWB antenna array for real beam radar imaging," International Conference on Applications of Electromagnetism and Student Innovation Competition Awards (AEM2C 2010), 284-288, Aug. 2010.

[20] Chen, M. and J. Wang, "Planar UWB antenna array with CPW feeding network," Proceedings of Asia-Pacific Microwave Conference (APMC 2008), 1-4, 2008. 


\section{"تصميم مقترح لهوائى أحادى القطبية على النطاق الترددى العريض ومصفوفاته الخطية"

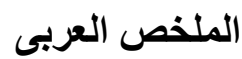

تم عمل تصميم مقترح لهو ائى صغير الحجم أحادى القطبية لكى يغطى النطاق الترددى العريض (2.49-

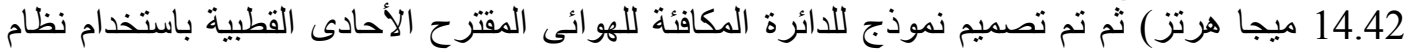

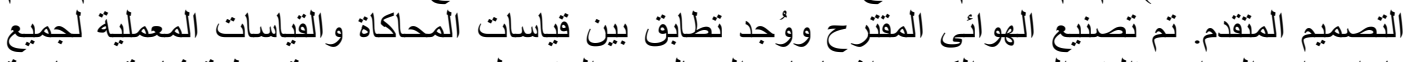

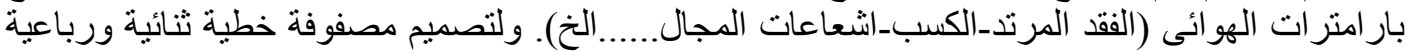

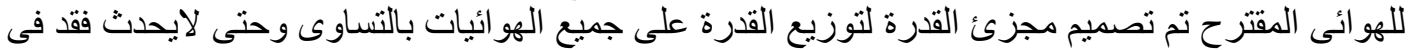

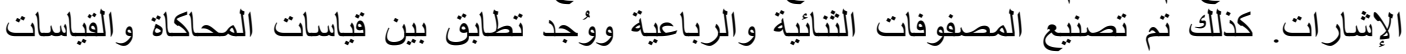

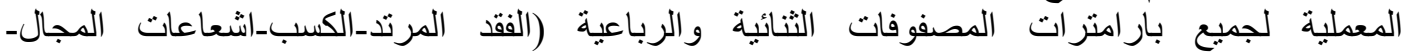

